\title{
Biovidro 45S5: um avanço biotecnológico nos materiais restauradores da odontologia
}

\section{Bioglass 45S5: the biotechnology advance in restorative dentistry materials}

\author{
Mayara Cristina Abas Frazão \\ Mestre em Odontologia, Programa de Pós-Graduação \\ em Odontologia, UFMA Universidade Federal do Maranhão \\ Gabrielle Vieira da Silva \\ Graduada em Nutrição, Faculdade Santa Terezinha, CEST
}

THATYLA SiLVA LinHaRES Mestranda em Odontologia, Programa de Pós-Graduação em Odontologia, UFMA Universidade Federal do Maranhão.

Andrea Dias Neves Lago Professora Doutora do Programa de Pós-Graduação em Odontologia, Faculdade de Odontologia UFMA Universidade Federal do Maranhão

DarLon MARTINS LIMA Coordenador do Programa de Pós-Graduação em Odontologia, Faculdade de Odontologia UFMA Universidade Federal do Maranhão.

\begin{abstract}
RESUMO
INTRODUÇÃO: Diante dos avanços tecnológicos, tem ocorrido um aumento na expectativa de vida, favorecendo o desenvolvimento de estudos em novos materiais que auxiliem na manutenção da vida humana. Tal abordagem viabiliza alternativas para substituição e reparos por tecidos sofridos por fraturas, traumas e patologias. E é nesse contexto que os biomateriais foram criados, com o intuito de estar em contato e interagir com o sistema biológico. OBJETIVO: realizar um levantamento literário com o intuito de analisar artigos de alto impacto sobre o Bioglass ${ }^{\circledR} 45 \mathrm{~S} 5$ na aplicação em materiais odontológicos. METODOLOGIA: foi realizada uma busca nas bases de dados do Pubmed e Sciencedirec. Os descritores utilizados foram: "bioglass, adhesive, enamel, dentin". RESULTADOS: após os critérios de inclusão e exclusão empregados, dos 16 estudos experimentais encontrados, $81 \%$ estavam relacionados à hipersensibilidade, remineralização e cimento de ionômero de vidro e os 19\% à resina e adesivo. Dos estudos, $100 \%$ apresentaram resultado satisfatório com o uso do biovidro. CONCLUSÃO: está concretizado na literatura a eficácia do Biovidro na aplicação in vitro na dentística. No entanto, novas pesquisas com teste de bioatividade, culturas celulares e aplicação in vivo, ainda, precisam ser testadas para o desenvolvimento na sua aplicabilidade clínica.
\end{abstract}

Palavras-chave: Biovidro; Materiais odontológicos; Eficácia.

\section{ABSTRACT}

INTRODUCTION: Given the technological advances, there has been an increase in life expectancy, favoring the development of studies on new materials that assist in the maintenance of human life. Such an approach enables alternative for replacement and repair of tissues suffered fractures, traumas and diseases. It is in this context that the biomaterials were created in order to be in touch and interact with the biological system. OBJECTIVE: To conduct a literature survey in order to analyze high-impact articles on the $45 \mathrm{~S} 5$ Bioglass ${ }^{8}$ the application in dental materials. METHODOLOGY: We performed a search in the databases of Pubmed and Sciencedirec. The descriptors used were: "bioglass, adhesive, enamel, dentin". RESULTS: After the criteria for inclusion and exclusion employees, of 16 studies found, $81 \%$ were related to hypersensitivity, and remineralization glass ionomer cement and $19 \%$ to the resin and adhesive. All studies showed satisfactory results with the use of bioglass. CONCLUSION: is realized in the literature the efficacy of bioglass in applying in vitro in dentistry. However new research with bioactivity test, cell culture and in vivo application also need to be tested for development in its clinical applicability.

Keywords: Bioglass; Dental materials; Effectiveness. 


\section{INTRODUÇÃO}

O desenvolvimento em materiais no auxílio da manutenção da saúde e no aumento na expectativa de vida da população tem viabilizado alternativas no tratamento de reparos de tecidos, in vitro e in vivo. Tal abordagem tem utilizado os biomateriais na interação, potencialização e regeneração das funções dos tecidos vivos, por meio do comportamento bioinerte, bioativo e bioestável desse material. ${ }^{1}$

Entre os biomateriais existentes na odontologia, enquadram-se os biovidros, que têm por finalidade a união entre o tecido e o material promovido pela resposta biológica. Isso ocorre devido à similaridade química com a estrutura óssea, permitindo ligações entre eles e a consequente osteocondução por meio do recobrimento por células ósseas. ${ }^{2-3}$

Estudos afirmam que os biovidros apresentam boa biocompatibilidade e resistência à corrosão e à compressão. No entanto, são materiais de pouca resistência mecânica, alta densidade e baixa resistência à fratura. ${ }^{4-6}$ Como solução a essa problemática, pesquisadores utilizaram suportes de polímero biodegradável, que possuem uma boa biocompatibilidade mecânica com a hidroxiapatita (HA), fornecendo uma resistência mecânica superior. A atuação desses compósitos ocorre onde há mais tensão de deformação no material. ${ }^{4-5}$

Civilizações antigas, como os egípcios, chineses e indianos, já usavam biomateriais para reconstruir as partes defeituosas do corpo, mas o Biovidro só foi utilizado para o uso clínico em 1969, por Larry Hench, na Universidade da Flórida. ${ }^{7}$ A sua descoberta originou-se por questionamentos de possíveis interações dos materiais bioativos ao corpo humano. A grande descoberta foi o Biovidro® 45S5, de composição 46,1 mol. \% SiO $, 24,4$ mol. \% $\mathrm{Na}_{2} \mathrm{O}, 26,9$ mol.\% $\mathrm{CaO}$ e 2,6 mol. \% de $\mathrm{P}_{2} \mathrm{O} 5$, desenvolvendo um vínculo forte com o osso, que só poderia ser removido se houvesse a sua quebra. ${ }^{8}$
O Biovidro® 4555 é um cálcio, fosfato de sódio e filossilicato bioativo, que estimula a formação de hidroxiapatita $\left[\mathrm{Ca} 10\left(\mathrm{PO}_{4}\right) 6(\mathrm{OH})_{2}\right]$ e a remineralização dos tecidos duros dentários, por meio da reação com os fluídos corporais. ${ }^{9-10} \mathrm{Na}$ Odontologia, o ar abrasivo do Biovidro® pode ser utilizado para remover os tecidos dentais duros, como, esmalte, dentina e cemento. A utilização do Biovidro® por meio de ar abrasivo possui grandes vantagens na preparação das cavidades com ângulos internos arredondados, proporcionando a menor tensão de contração dos compósitos, a ausência de dor durante os procedimentos e a remoção seletiva da dentina cariada. ${ }^{11-12}$

Estudos evidenciaram, in vitro, a interação dos vidros bioativos com a dentina humana após imersão em saliva, e que todo Biovidro $®$ $45 \mathrm{~S} 5$ pode aderir à dentina sob estas condições. ${ }^{13}$ Além disso, em 2012, Osório et al. ${ }^{14}$ mostraram que há efetividade do Biovidro® $45 S 5$ sobre limitação das metaloproteinases e o favorecimento na remineralização dentária. Dessa forma, visando encontrar evidências científicas em atuação e longevidade química adequada do Biovidro® $45 S 5$ na execução da sua função como matriz e absorção pelo tecido vivo, este trabalho desenvolveu uma revisão de literatura com o objetivo de levantar e analisar artigos de alto impacto literário sobre esse material na aplicação em materiais restauradores na Odontologia.

\section{Metodologia}

Este estudo teve como metodologia uma busca ativa de informações nas bases de dados do Pubmed e Science direct. Procurou-se realizar uma pesquisa bibliográfica sobre 0 tema central deste trabalho, Biovidros $₫ 45 S 5$.

Com a finalidade de delimitar o objeto do estudo e o campo de investigação, optou-se como critério de inclusão, apenas artigos voltados para pesquisa em humanos, revisões de 
literatura e no período de pesquisa dos últimos 10 anos, 2005 a 2015. Foram excluídos da nossa busca artigos não publicados e estudos em animais.

Os descritores utilizados para a busca de artigos a respeito de "biovidros" foram: "bioglass, adhesive, enamel, dentin". Para a localização de artigos sobre o assunto, realizou-se o uso individual e o agrupamento dos descritores, sendo localizados como, bioglass enamel - 20 artigos, bioglass dentin - 32 artigos, bioglass adhesive -6 artigos e bioglass - 709 artigos.
A seleção dos artigos baseou-se na limitação dos assuntos aos objetivos deste trabalho, sendo desconsiderados por três etapas. Inicialmente pelo título, em seguida pelo resumo e, por fim, pelo texto do artigo que, apesar de aparecerem no resultado da busca, não abordavam o assunto sob o ponto de vista do trabalho. No final da busca, foram utilizados 29 artigos, sendo 26 artigos experimentais e quatro revisões de literatura, para a construção desta revisão literária.

\section{Resultados}

De acordo com o objetivo do trabalho, os resultados foram demonstrados no quadro 1 e gráficos 1 e 2 .

Quadro 1. Análise das evidências científicas encontradas

\begin{tabular}{|c|c|c|c|c|}
\hline Autor & Objetivo & Metodologia & $\begin{array}{c}\text { Meio de } \\
\text { armazenamento }\end{array}$ & Resultado \\
\hline $\begin{array}{l}\text { Lee et al., } \\
2005^{15}\end{array}$ & $\begin{array}{c}\text { Analisar in vitro } \\
\text { a pasta DP-vidro } \\
\text { no tratamento da } \\
\text { hipersensibilidade } \\
\text { dentinária }\end{array}$ & $\begin{array}{l}\text { Foi preparado uma pasta DP- } \\
\text { biovidro com uma mistura de } \\
20 \% \text { a } 60 \% \text { de ácido fosfórico. A } \\
\text { irradiação do laser } \mathrm{CO}_{2} \text { foi utilizada } \\
\text { para fundir a pasta DP-biovidro, } \\
\text { com a finalidade de bloquear os } \\
\text { túbulos dentinários expostos } \\
\text { Grupo I: DP-Biovidro + } 20 \% \text { ácido } \\
\text { fosfórico + laserCO ; Grupo II: } \\
\text { DP-Biovidro + } 60 \% \text { ácido fosfórico } \\
+ \text { laser } \mathrm{CO}_{2}\end{array}$ & Não relatado & $\begin{array}{l}\text { A concentração que apresentou melhor } \\
\text { resultado na obstrução dos túbulos } \\
\text { dentinários foi de } 30 \% \text { de ácido } \\
\text { fosfórico e } 60 \mu \mathrm{m} \text { de profundidade de } \\
\text { vedação } \\
\text { Irradiação com laser de } \mathrm{CO}_{2} \text { poderia } \\
\text { derreter a pasta DP- biovidro e criar } \\
\text { cerca de } 10 \mu \mathrm{m} \text { de profundidade de } \\
\text { vedação } \\
\text { A pasta DP- biovidro pode produzir } \\
\text { uma vedação dos túbulos dentinários, } \\
\text { podendo prolongar o efeito terapêutico }\end{array}$ \\
\hline $\begin{array}{l}\text { Lee et al., } \\
2005^{16}\end{array}$ & $\begin{array}{l}\text { Analisar o efeito } \\
\text { do biovidro com o } \\
\text { auxílio da irradiação } \\
\text { de um laser Nd: } \\
\text { YAP para conseguir } \\
\text { melhor vedação dos } \\
\text { túbulos dentinários }\end{array}$ & $\begin{array}{l}\text { Utilizaram } 20 \text { molares humanos } \\
\text { com } 4 \text { parâmetros de energia para } \\
\text { difundir o biovidro de composição } \\
\text { modificada } \\
\text { Grupo I: Biovidro + Nd: } \\
\text { YAP 30Hz,330mJ. Grupo II: } \\
\text { Biovidro. +Nd: YAP30Hz, 160mJ } \\
\text { Grupo III: Biovidro + Nd: YAP } \\
\text { 10hZ, 400mJ. } \\
\text { Grupo IV: Biovidro + Nd: YAP } \\
\text { 10Hz,200 mJ. }\end{array}$ & $\begin{array}{c}\text { Água destilada }+ \\
0,2 \text { timol }\end{array}$ & $\begin{array}{l}\text { As profundidades obstrutivas } \\
\text { dos túbulos de } 2 \text { e } 10 \text { mm foram } \\
\text { alcançadas quando o biovidro sofreu } \\
30 \mathrm{~Hz}, 160 \mathrm{~mJ} / \text { pulso (modo GK) e } 30 \\
\mathrm{~Hz}, 330 \mathrm{~mJ} / \text { pulso (modo GC) } \\
\text { Não foi observado fases de } \\
\text { transformação após o uso do laser Nd: } \\
\text { YAP. } \\
\text { A utilização do biovidro acrescido do } \\
\text { laser Nd: YAP tem o potencial de uso } \\
\text { clínico para tratar a hipersensibilidade } \\
\text { da dentina }\end{array}$ \\
\hline $\begin{array}{l}\text { Chun Kuo } \\
\text { et al., } 2007^{17}\end{array}$ & $\begin{array}{l}\text { Investigar o efeito } \\
\text { citotóxico da pasta } \\
\text { DP-biovidro, em } \\
\text { material restaurador } \\
\text { intermediário } \\
\text { (IRM) e um agente } \\
\text { dessensibilizante } \\
\text { (Abmindent), em } \\
\text { células pulpares de } \\
\text { dentes humanos }\end{array}$ & $\begin{array}{l}\text { Utilizaram } 25 \text { molares de dentes } \\
\text { humanos extraídos de indivíduos } \\
\text { de } 16 \text { a } 40 \text { anos } \\
\text { Grupo I: Material restaurador } \\
\text { intermediário (IRM); Grupo II: } \\
\text { Pasta de vidro DP-Biovidro; } \\
\text { Grupo III: Pó de vidro DP- } \\
\text { Biovidro; Grupo IV: Albmindent } \\
\text { (dessensibilizante) }\end{array}$ & $\begin{array}{l}\text { Soro fetal a } 10 \% \\
\text { com penicilina / } \\
\text { estreptomicina }\end{array}$ & $\begin{array}{l}\text { Não houve diferença significativa entre } \\
\text { IRM, pasta DP-biovidro e Abmindent. } \\
\text { O DP-Biovidro tem capacidade de } \\
\text { atingir profundamente a vedação } \\
\text { dos túbulos, sendo considerado um } \\
\text { material potencial para o tratamento da } \\
\text { hipersensibilidade dentinária }\end{array}$ \\
\hline
\end{tabular}




\begin{tabular}{|c|c|c|c|c|}
\hline Autor & Objetivo & Metodologia & $\begin{array}{c}\text { Meio de } \\
\text { armazenamento }\end{array}$ & Resultado \\
\hline $\begin{array}{l}\text { Lee et al., } \\
2007^{18}\end{array}$ & $\begin{array}{l}\text { Verificar in vitro } \\
\text { o uso do sol-gel } \\
\text { DP-biovidro no } \\
\text { fechamento dos } \\
\text { túbulos dentinários } \\
\text { para o tratamento da } \\
\text { hipersensibilidade } \\
\text { dentinária }\end{array}$ & $\begin{array}{l}\text { Utilizaram o sol-gel DP-biovidro } \\
\text { em } 1203^{\circ} \text { molares no tratamento } \\
\text { da hipersensibilidade dentinária } \\
\text { Grupo A-D: grupo catalizadores } \\
\left(\mathrm{HNO}_{3}, \mathrm{NaOH}, \mathrm{H}_{3} \mathrm{PO}_{4}\right) \text {; grupo } \\
\text { controle (DP-Biovidro) } \\
\text { Grupo E-F: One Coat Bond; Self } \\
\text { \& Protect }\end{array}$ & $\begin{array}{c}\text { Água destilada }+ \\
0,2 \text { timol }\end{array}$ & $\begin{array}{l}\text { O melhor desempenho de obstrução } \\
\text { do túbulo dentinário foi pelo DP- } \\
\text { biovidro catalisado com HNO } \\
\text { O desempenho do DP-biovidro } \\
\text { foi melhor que Seal \& Protect, } \\
\text { apresentando o maior potencial no } \\
\text { tratamento da hipersensibilidade } \\
\text { dentinária }\end{array}$ \\
\hline $\begin{array}{l}\text { Curtis et } \\
\text { al., } 2010^{19}\end{array}$ & $\begin{array}{c}\text { Avaliar a formação } \\
\text { de apatita nos } \\
\text { túbulos dentinários } \\
\text { e o fim da } \\
\text { hipersensibilidade } \\
\text { com a fusão de um } \\
\text { nanovidro sol-gel e o } \\
\text { biovidro }\end{array}$ & $\begin{array}{l}\text { Foram utilizados dois grupos } \\
(\mathrm{n}=12) \\
\text { Grupo I: Biovidro Sol-gel; } \\
\text { Grupo II: Fusão de pó de } \\
\text { Biovidros }\end{array}$ & Saliva humana & $\begin{array}{l}\text { O Grupo II resultou na formação } \\
\text { de apatita, firmemente aderente, } \\
\text { obstruindo túbulos dentinários } \\
\text { expostos } \\
\text { O biovidro de tamanho mícron formou } \\
\text { uma camada de apatita sobre a } \\
\text { superfície da dentina. Já o biovidro } \\
\text { nanométricos formou hastes de apatita } \\
\text { dentro dos túbulos dentinários }\end{array}$ \\
\hline $\begin{array}{l}\text { Chiang et } \\
\text { al., } 2010^{20}\end{array}$ & $\begin{array}{l}\text { Criar nanopartículas } \\
\text { de CaO com um } \\
\text { biomaterial de sílica } \\
\text { mesoporosa (NCMS) } \\
\text { e testar a sua } \\
\text { mistura com } 30 \% \text { de } \\
\text { ácido fosfórico para } \\
\text { avaliar a efetividade } \\
\text { na obstrução dos } \\
\text { túbulos dentinários }\end{array}$ & $\begin{array}{l}48 \text { molares humanos foram } \\
\text { divididos em grupos }(n=16) \text { para } \\
\text { o tratamento de superfície com } \\
\text { materiais dessensibilizantes } \\
\text { Grupo I: Seal \& Protect } \\
\text { Grupo II: DP-Biovidro } \\
\text { Grupo III: NCMS (nano CaO } \\
\text { silíca mesoporosa) }\end{array}$ & $\begin{array}{c}\text { Água destilada }+ \\
0,2 \text { timol }\end{array}$ & $\begin{array}{l}\text { O Grupo III teve uma redução } \\
\text { significativa na permeabilidade da } \\
\text { dentina em relação ao grupo II e I } \\
\text { O Grupo III tem grandes potenciais de } \\
\text { aplicações para o tratamento clínico da } \\
\text { hipersensibilidade dentinária }\end{array}$ \\
\hline $\begin{array}{l}\text { Bakry et al., } \\
2011^{21}\end{array}$ & $\begin{array}{c}\text { Analisar as } \\
\text { características } \\
\text { micromorfológica e } \\
\text { química na superfície } \\
\text { dentária com ou sem } \\
\text { o uso do biovidro e } \\
\mathrm{O} \mathrm{CO}_{2}\end{array}$ & $\begin{array}{l}\text { Estudaram } 76 \text { terceiros molares } \\
\text { humanos não cariados } \\
\text { Grupo I: Não foi aplicada biovidro } \\
\text { + sem laser; Grupo II: Biovidro } \\
\text { não foi aplicado + laser de } \mathrm{CO}_{2} \text {; } \\
\text { Grupo III: biovidro + sem laser } \\
\text { de } \mathrm{CO}_{2} \text {; Grupo IV: biovidro +laser } \\
\text { de } \mathrm{CO}_{2}^{2}\end{array}$ & Água ionizada & $\begin{array}{l}\text { O resultado mais eficaz foi obtido pelos } \\
\text { grupos III e IV. } \\
\text { A camada formada nas superfícies } \\
\text { dentinária no grupo III apresentaram } \\
\text { placas planas de cristal grandes, no } \\
\text { grupo IV foram mais compactas e no } \\
\text { grupo III exibiram cristais menores } \\
\text { O biovidro } 45 S 5 \text { pode obstruir os } \\
\text { túbulos dentinários com cristais de } \\
\text { fosfato de cálcio. A aplicação do } \\
\text { laser de } \mathrm{CO}_{2} \text { melhorou a organização } \\
\text { mecânica desses cristais }\end{array}$ \\
\hline $\begin{array}{l}\text { Farmakis et } \\
\text { al., } 2012^{22}\end{array}$ & $\begin{array}{l}\text { Avaliar a eficácia } \\
\text { de NovaMin e } \\
\text { o laser Nd:YAG } \\
\text { no tratamento } \\
\text { da sensibilidade } \\
\text { dentinária }\end{array}$ & $\begin{array}{l}\text { Analisaram } 48 \text { molares humanos } \\
\text { com a dentina cervical exposta } \\
\text { Grupo I: Pasta NovaMin (NM); } \\
\text { Grupo II: Nd: YAG (0,5 W, } 10 \mathrm{~Hz} \\
\text { e } 50 \text { mJ) (L); Grupo III: NM + L; } \\
\text { Grupo IV: L + NM }\end{array}$ & $\begin{array}{c}\text { Soro fisiológico } \\
\text { estéril }\end{array}$ & $\begin{array}{l}\text { O grupo I teve menos obliteração dos } \\
\text { túbulos dentinários } \\
\text { Irradiação do laser sozinho e em } \\
\text { combinação com NM mostrou-se } \\
\text { superior na obliteração dos túbulos } \\
\text { dentinários do que o NM sozinho }\end{array}$ \\
\hline $\begin{array}{c}\text { Vollenwe- } \\
\text { uder et al., } \\
2007^{23}\end{array}$ & $\begin{array}{l}\text { Analisar a remoção } \\
\text { de dentina cariada } \\
\text { usando ar abrasivo } \\
\text { de vidro bioativo e } \\
\text { a retenção de suas } \\
\text { partículas abrasivas } \\
\text { e da alumina em } \\
\text { dentina desgastada }\end{array}$ & $\begin{array}{l}\text { Foram utilizados } 10 \text { molares } \\
\text { humanos cariados. } \\
\text { Grupo I: Nanoparticulas de } \\
\text { biovidros (NBG, } 45 S 5) ; \\
\text { Grupo II: Perioglas (PG) }\end{array}$ & $\begin{array}{c}\text { Solução de timol } \\
0,2 \%\end{array}$ & $\begin{array}{l}\text { Após o tratamento por } 10 \text { ou } 30 \\
\text { dias, o grupo I teve um aumento na } \\
\text { remineralização rápida de dentina } \\
\text { As propriedades mecânicas das } \\
\text { amostras de dentina remineralizada } \\
\text { ficaram bem abaixo da estabilidade da } \\
\text { dentina natural } \\
\text { A remineralização foi facilitada pelo } \\
\text { grupo I em relação ao II }\end{array}$ \\
\hline $\begin{array}{l}\text { Paolinelis } \\
\text { et al., } 2008^{12}\end{array}$ & $\begin{array}{c}\text { Analisar a taxa de } \\
\text { remoção de dentina } \\
\text { cariada amolecida } \\
\text { com o uso do ar } \\
\text { abrasivo de vidro } \\
\text { bioativo e investigar } \\
\text { a retenção de } \\
\text { partículas abrasivas } \\
\text { de vidro bioativo e } \\
\text { alumina em dentina } \\
\text { desgastada }\end{array}$ & $\begin{array}{c}\text { Foram utilizados } 10 \text { molares } \\
\text { cariados } \\
\text { Grupo1: Abrasão com alumina - } \\
\text { Subgrupo 1.1: Abrasivo } 138 \mathrm{kPa} \\
\text {-Subgrupo1.2: Abrasivo } 413 \mathrm{kPa} \\
\text {-Subgrupo1.3: Abrasivo } 689 \mathrm{kPa} \\
\text { Grupo2: Abrasão com vidro } \\
\text { bioativo } \\
\text {-Subgrupo2.1: Abrasivo } 138 \mathrm{kPa} \\
\text {-Subgrupo2.2: Abrasivo } 413 \mathrm{kPa} \\
\text {-Subgrupo2.3: Abrasivo } 689 \mathrm{kPa}\end{array}$ & Em água & $\begin{array}{l}\text { Houve uma maior retenção do grupo II } \\
\text { do que o I na dentina } \\
\text { A dentina sadia foi removida pelo } \\
\text { biovidro a um ritmo menos elevado } \\
\text { do que a dentina cariada. O grupo II } \\
\text { tornou-se potencialmente mais seletivo } \\
\text { para remoção clínica de cárie } \\
\text { Embora o alumínio não fosse } \\
\text { detectado nas amostras de controle, } \\
\text { foi detectado nas amostras de vidros } \\
\text { bioativos e presença de sílica nas } \\
\text { amostras de alumina }\end{array}$ \\
\hline
\end{tabular}




\begin{tabular}{|c|c|c|c|c|}
\hline Autor & Objetivo & Metodologia & $\begin{array}{c}\text { Meio de } \\
\text { rmazenamento }\end{array}$ & Resultado \\
\hline $\begin{array}{l}\text { Osorio et } \\
\text { al, } 2012^{24}\end{array}$ & $\begin{array}{l}\text { Determinar se } \\
\text { cimento contendo } \\
\text { material bioativo } \\
\text { pode controlar a } \\
\text { degradação da } \\
\text { matriz de colágeno } \\
\text { mediada pela } \\
\text { metaloproteinases } \\
\text { (MMPs) de dentina } \\
\text { condicionada }\end{array}$ & $\begin{array}{l}\text { Dentes humanos foram usados } \\
\text { com 10\% de ácido fosfórico ou } \\
0,5 \text { mol/L de EDTA em resinas } \\
\text { experimentais } \\
\text { Grupo I: EDTA +ausência de } \\
\text { infiltração de resina; Grupo II: } \\
\text { EDTA +Resina com infiltração; } \\
\text { Grupo III: EDTA + Resina } \\
\text { infiltrada com fosfato b-tricálcio + } \\
\text { cimento modificado de silicato de } \\
\text { cálcio (Hcat-b); Grupo IV: EDTA } \\
\text { +Resina infiltrada com 45S5 } \\
\text { Biovidro }\end{array}$ & Saliva humana & $\begin{array}{l}\text { A degradação de colágeno foi maior } \\
\text { tanto em ácido fosfórico como com } \\
\text { EDTA em dentina } \\
\text { Infiltração de resina reduziu a atividade } \\
\text { das MMPs em dentina desmineralizada } \\
\text { O grupo IV é mais eficaz na proteção } \\
\text { de colágeno e remineralização } \\
\text { O grupo III agiu no colágeno pelas } \\
\text { MMPs apenas em amostras tratadas } \\
\text { com EDTA } \\
\text { A degradação MMPs dentina é } \\
\text { fortemente reduzida em resina } \\
\text { infiltrada em dentina }\end{array}$ \\
\hline $\begin{array}{l}\text { Sauro, } \\
2012^{25}\end{array}$ & $\begin{array}{l}\text { Testar a resistência } \\
\text { à microtração de um } \\
\text { cimento de ionômero } \\
\text { de vidro modificado } \\
\text { por resina ligada à } \\
\text { dentina pré-tratada } \\
\text { com Biovidro } 45 S 5, \\
\text { utilizando várias } \\
\text { técnicas de ataque } \\
\text { ácidos e ar-abrasivo }\end{array}$ & $\begin{array}{l}\text { Grupo I: carbeto sílico (SiC)+ } \\
\text { cimento de ionômero de vidro } \\
\text { modificado por resina (ClOVMR); } \\
\text { Grupo II: SiC + ácido poliacrílico } \\
\text { 10\% PAA + ClOVMR; Grupo III: } \\
\text { partículas biovidro+ CIOVRM; } \\
\text { Grupo IV: ar abrasivo com } \\
\text { biovidro + PAA } 10 \%+\text { CIOVRM; } \\
\text { Grupo V: biovidro +PAA 10\% } \\
+ \text { CIOVRM; Grupo VI: ar } \\
\text { abrasivo com biovidro + PAA } \\
10 \%+\text { gel PAA } 10 \%+\text { CIOVRM }\end{array}$ & $\begin{array}{l}\text { Solução tampão de } \\
\text { fosfato }\end{array}$ & $\begin{array}{l}\text { A camada de interface CIOVRM } \\
\text { na dentina não mostrou nenhuma } \\
\text { absorção de água, exceto por } \\
\text { interdifusão da camada de SiC- } \\
\text { abrasivada / PAA } \\
\text { Os procedimentos do grupo IV e } \\
\text { V podem ser uma estratégia para } \\
\text { melhorar a durabilidade e a capacidade } \\
\text { de ligação de cura CIOVRM ligada à } \\
\text { dentina } \\
\text { Os procedimentos com ar abrasivo } \\
\text { utilizando uma combinação de biovidro } \\
\text { e de fluido PAA, ao invés de biovidro e } \\
\mathrm{H}_{2} \mathrm{O} \text {, podem aumentar a incorporação } \\
\text { de partículas de biovidro na dentina }\end{array}$ \\
\hline $\begin{array}{l}\text { Mousavina- } \\
\text { sab, } 2011^{26}\end{array}$ & $\begin{array}{l}\text { Comparar as } \\
\text { forças de flexão do } \\
\text { ionômero de vidro } \\
\text { modificado por resina } \\
\text { contendo vidro } \\
\text { bioativo e com uma } \\
\text { resina modificada }\end{array}$ & $\begin{array}{c}\text { Grupo I: Ionômero de vidro } \\
\text { modificado por resina contendo } \\
\text { vidro bioativo (RMGI-BAG) Grupo } \\
\text { II: lonômero de vidro modificado } \\
\text { por resina (RMGI) }\end{array}$ & Não relatado & $\begin{array}{l}\text { A adição de } 20 \% \text { em peso do pó de } \\
\text { biovidro diminui a força de flexão do } \\
\text { material } \\
\text { A resistência à flexão do grupo II é } \\
\text { menor do que a do grupo I, mas ainda } \\
\text { é clinicamente aceitável }\end{array}$ \\
\hline $\begin{array}{l}\text { Hashimo- } \\
\text { to, } 2010^{27}\end{array}$ & $\begin{array}{l}\text { Avaliar o efeito da } \\
\text { composição do } \\
\text { monômero de resina } \\
\text { sobre o crescimento } \\
\text { de cristais na } \\
\text { interface da resina/ } \\
\text { biovidro }\end{array}$ & 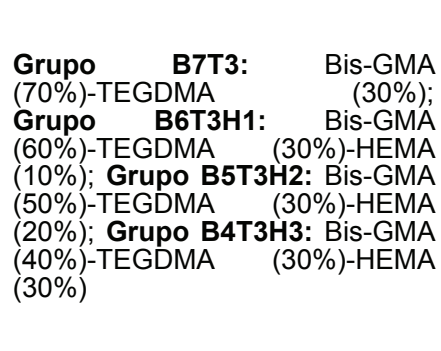 & $\begin{array}{l}\text { Água destilada } \\
24 \mathrm{hr} \text { (grupo } \\
\text { controle) 3-12 } \\
\text { meses (grupo } \\
\text { experimental) }\end{array}$ & $\begin{array}{l}\text { Presença de cristal na superfície dos } \\
\text { discos de resina após } 6 \text { meses de } \\
\text { armazenamento em água, no grupo } \\
\text { B4T3H3 } \\
\text { Não houve formação de cristais } \\
\text { no grupo controle e os grupos } \\
\text { experimentais, mas houve a formação } \\
\text { de cristais na matriz de resina e } \\
\text { biovidro } \\
\text { As composições de monômero da } \\
\text { resina têm capacidade de crescimento } \\
\text { de cristais em discos contendo biovidro }\end{array}$ \\
\hline $\begin{array}{l}\text { Sauro, } \\
2012^{28}\end{array}$ & $\begin{array}{l}\text { Avaliar os efeitos } \\
\text { de dois sistemas de } \\
\text { colagem de resinas } \\
\text { contendo Biovidro } \\
45 S 5 \text { convencional } \\
\text { ou vidro bioativo } \\
\text { com microfilamentos } \\
\text { de policarboxilato } \\
\text { de zinco ligado na } \\
\text { interface resina- } \\
\text { dentina }\end{array}$ & $\begin{array}{l}\text { Grupo A: Resina (Biovidro); } \\
\text { Grupo B: Resina (Biovidro + } \\
\text { Policarboxilato de zinco); Grupo } \\
\text { C: Resina (sem enchimento) }\end{array}$ & $\begin{array}{l}\text { Solução de fluido } \\
\text { corporal simulado }\end{array}$ & $\begin{array}{l}\text { A resina do grupo A e B mostrou } \\
\text { uma presença de apatita, redução } \\
\text { da micropermeabilidade dentro da } \\
\text { interface resina-dentina e um aumento } \\
\text { dos módulos de elasticidade e dureza } \\
\text { na interface de união } \\
\text { Os grupos A e B têm um efeito } \\
\text { terapêutico sobre as propriedades } \\
\text { nano-mecânicas e capacidade de } \\
\text { vedação na interface resina-dentina }\end{array}$ \\
\hline $\begin{array}{l}\text { Sauro, } \\
2012^{29}\end{array}$ & $\begin{array}{l}\text { Testar a resistência } \\
\text { à microtração de } \\
\text { dois adesivos } \\
\text { autocondicionantes } \\
\text { ligados à dentina } \\
\text { por ar-abrasivo com } \\
\text { o uso experimental } \\
\text { de pó de biovidro } \\
\text { contido no ácido } \\
\text { poliacrilíco }\end{array}$ & $\begin{array}{l}\text { Grupo I: Grupo controle: SiC } \\
\text { (carbeto de silica) + adesivo + } \\
\text { compósito; Grupo II: Ar-abrasivo } \\
\text { com 100\% Biovidro+ adesivo } \\
\text { +compósito; Grupo III: Ar- } \\
\text { abrasivo com Biovidro + PAA 15\% } \\
\text { + adesivo + compósito; Grupo IV: } \\
\text { Ar-abrasivo com Biovidro 60\% + } \\
\text { PAA 40\% + adesivo +compósito }\end{array}$ & $\begin{array}{l}\text { Solução tampão de } \\
\text { fosfato }\end{array}$ & $\begin{array}{l}\text { Entre os adesivos autocondicionantes, } \\
\text { o sistema adesivo Cleafil S3 alcançou } \\
\text { índices mais elevados no teste de } \\
\text { microtração do que o G. James Bond } \\
\text { após } 24 \text { h e } 6 \text { meses de armazenagem } \\
\text { A análise confocal indicou } \\
\text { micropermeabilidade grave nas } \\
\text { interfaces adesivo dentina usando } \\
\text { G. James Bond GB com Biovidros / } \\
\text { ácido poliacrilico - } 15 \text { e Biovidro/ácido } \\
\text { poliacrilico-40 } \\
\text { Cleafil S3 não exibiram nenhuma } \\
\text { micropermeabilidade na interface } \\
\text { resina-dentina }\end{array}$ \\
\hline
\end{tabular}


Diante dos 16 artigos experimentais encontrados, $81 \%$ dos achados literários acometeram estudos do biovidro relacionados à hipersensibilidade, remineralização e cimento de ionômero de vidro, e os $19 \%$ restantes englobaram os estudos relacionados à resina $\mathrm{e}$ adesivo (Gráfico 1).

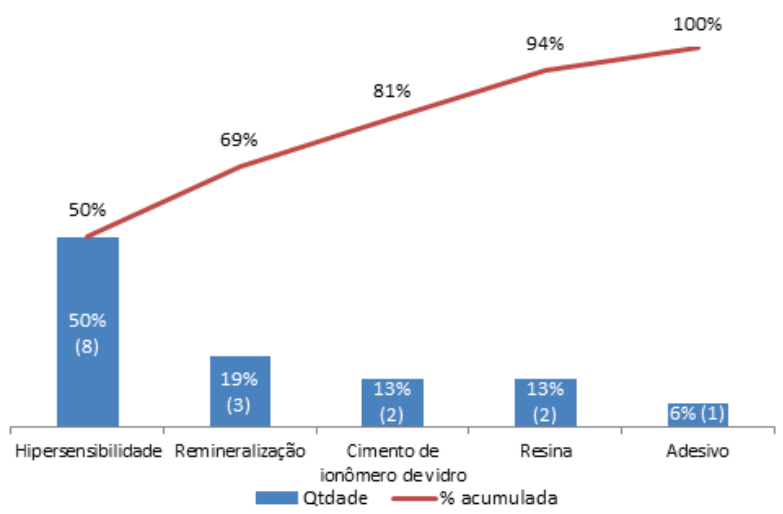

Gráfico 1. Gráfico de Pareto, representando $\%$ de prevalência dos estudos encontrados.

A prevalência dos estudos levantados e analisados, separando-os por cinco grupos, e os relacionando com resultados satisfatórios ou insatisfatórios com o uso do biovidro está expressa no Gráfico 2.

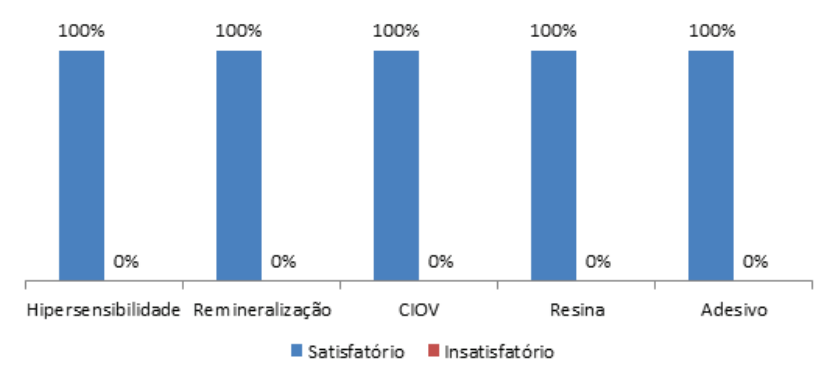

Gráfico 2. Gráfico de barra demonstrando $\%$ de dados estratificados por assunto

\section{Dıscussão}

Este levantamento bibliográfico teve o desígnio de demonstrar os estudos em biotecnologia de materiais restauradores dentários, com o tema central de Biovidros $₫$ 45S5. Nesta análise, dos 16 artigos analisados foram ob- servados resultados satisfatórios em 100\% dos achados literários.

Estudo prévio, 2013, comprovou que as partículas do Biovidro ${ }^{2} 45 S 5$ têm capacidade de adesão à dentina e formação de camada de hidroxiapatita semelhante à composição do esmalte dos dentes e túbulos dentinários. ${ }^{7}$ Os dados encontrados foram convergentes ao estudo de Lee et al. ${ }^{15}$ Já, Bor-Shiunn et al., ${ }^{16}$ associaram o biovidro com a irradiação a laser, obtendo uma melhor vedação na profundidade dos túbulos dentinários e um efeito terapêutico prolongado. Nesse cenário, em 2012, Bakry et al. ${ }^{21}$ analisaram o Biovidro $® 45 S 5$, misturado com ácido fosfórico e irradiado com laser de CO2 no tratamento da hipersensibilidade dentinária. Os resultados foram positivos, corroborando aos dados de Farmakis et al. ${ }^{22}$

Recentemente, o tratamento da hipersensibilidade com o uso do Biovidro® 4555 tem sido analisado e testado por vários pesquisadores. ${ }^{15-16,19-20,22}$ Em 2004, analisaram o uso de uma pasta com DP-biovidro no tratamento de sensibilidade dentinária, sendo constatado ser um material em potencial nessa terapêutica. ${ }^{17}$ Além disso, avaliaram a eficácia de um nanovidro sol-gel e pós de biovidros. Os resultados obtidos foram que o tratamento das amostras de dentina com pós de biovidro resultou na formação de apatita contínua, firmemente aderente, obstruindo os túbulos dentinários. Tal abordagem pode ser justificada pela formação de apatita por hidrólise da rede de silicato para produzir uma solução iônica supersaturada, onde íons de sílica sobre a superfície de dentina são condensados e ocorre a cristalização subsequente de um fosfato de cálcio amorfo, resultando na formação de apatita. ${ }^{19}$

Em 2010, pesquisadores utilizaram NCMS (nano $\mathrm{CaO}$ silíca mesoporosa) misturado com $30 \%$ de ácido fosfórico, demonstrando um desempenho na redução da permeabilidade da dentina e tratamento da hipersensibilidade dentinária, devido à precipitação relativamen- 
te rápida e a vedação hermética dos túbulos dentinários. Além disso, a pressão da polpa simulada durante o tratamento de superfície de dentina não interferiu com o desempenho da obstrução dos túbulos. ${ }^{20}$

Além disso, Vollenweuder et al. ${ }^{23}$ avaliaram se o vidro bioativo nanoparticulado tem capacidade de remineralização in vitro. O resultado obtido foi que a taxa de remineralização é mais elevada por partículas de vidro bioativos de tamanho nanométrico do que micrométrico. No entanto, os autores perceberam que as propriedades mecânicas das amostras de dentina remineralizada foram um pouco diferentes da estabilidade da dentina natural. O motivo dessa falta de reconstituição mecânica pode estar relacionado a um arranjo imperfeito do mineral recentemente depositado dentro da matriz do dente desmineralizado.

Paolinelis et al. ${ }^{12}$ perceberam que a dentina cariada foi removida pelo Biovidro $\AA 45 S 5$ a um ritmo mais elevado do que a dentina sadia, tornando a alumina menos seletiva para a remoção clínica de cárie. Além disso, observaram que o alumínio não foi encontrado nas amostras de controle, mas foi detectado nas amostras de vidros bioativos e a presença de sílica nas amostras de alumina. Como justificativa, os autores expõem duas razões: a peça de mão usada tinha uma seção de alumínio e pode ter sido desgastada internamente e a possibilidade de alguma contaminação cruzada durante a troca do material.

Em 2012, pesquisadores concluíram que a matriz de colágeno da dentina pode ser remineralizada na presença de materiais bioativos. ${ }^{14}$ Com isso, tiveram como resultado em outra pesquisa que a degradação das metaloproteinases da dentina é reduzida em resina infiltrada e que a inclusão de Biovidro ${ }^{\circledR} 45 S 5$ exerceu uma proteção ao colágeno da dentina durante a remineralização. Resultados convergentes foram obtidos por Curtis et al. ${ }^{19}$

A teoria contemporânea minimalista na preparação de cavidades restauradoras de- fende que a remoção de cárie deve resultar na remoção seletiva em dentina infectada, preservando a dentina afetada para possibilitar remineralização por materiais restauradores bioativos. ${ }^{12}$ Dados estes que foram ratificados pelo estudo de Sauro et al. ${ }^{29}$

Vale ressaltar que os avanços recentes em materiais dentários levaram à adição de materiais bioativos aos cimentos de ionômero, resultando em efeitos benéficos, além da liberação de flúor. Em 2011, avaliaram que a resistência à flexão de RMGI-BAG é maior do que a de RMGI. ${ }^{26}$ Já Hashimoto et al. ${ }^{27}$ 2010, perceberam que composições de monômero de resina afetam a capacidade de induzir o crescimento de cristais na superfície dos discos contendo biovidro, demonstrando que a formação de cristais é um comportamento comum em $40 \%$ dos biovidros com uma composição hidrófila, B4T3H3, em água, ao longo de seis meses. Resultados semelhantes foram encontrados em outro estudo. ${ }^{25}$

Os procedimentos de abrasão realizados com Biovidro $® 45 S 5$, em combinação com o ácido poliacrílico, podem ser uma estratégia adequada para melhorar a durabilidade do cimento de ionômero de vidro modificado por resina ligado à dentina. ${ }^{28}$ Além disso, Sauro et al. ${ }^{25}$ afirmaram que os sistemas de colagem de resina contendo filamentos bioativos podem ter um efeito terapêutico sobre as propriedades nano-mecânicas e capacidade de interface resina-dentina empobrecida em vedação.

\section{Conclusão}

Dessa forma, fica concretizada na literatura a eficácia do Biovidro® $45 S 5$ na aplicação in vitro em materiais odontológicos restauradores. No entanto, novas pesquisas com teste de bioatividade, culturas celulares e aplicação in vivo, ainda, precisam ser testadas com o intuito de obter maiores avanços na aplicabilidade clínica desse material. 


\section{REFERÊNCIAS}

1 Ramakrishna S, Meyer J, Wintermantel E, Leong KW. Biomedical applications of polymercomposite materials: A review. Comp Sci Tech 2001; 61: 1.189-1.224.

2 Kaur G, Pandey OP, Singh K, Homa D, Scott B, Pickrell G. A review of bioactive glasses: Their structure, properties, fabrication, and apatite formation. J Biomed Mater Res- Part A 2014; 102A: 254-274.

Hench LL, Polak JM. Third-generation biomedical materials. Science 2002; 295 (5577): 1.0141.017.

3 Rehman MN, Ray DE, Ball BS, FU Q, Jung SB, Bonewald LF, TOMSIA AP. Bioactive glass in tissue engineering. Acta Biomater 2011; 7(6): 2.355-2.373.

4 Zhang R, Ma PX. Poly (a-hydroxyl acids)/hydroxyapatite porous composites for bone tissue engineering I. Preparation and morphology. J Biomed Mater Res 1999; 44(4): 446-455.

$5 \mathrm{KIm}$ SS, Ahn KM, Park MS, Lee JH, Choi CY, Kim BS. A poly(lactide coglycolide/hydroxyapatite composite scaffold with enhanced osteoconductivity. J Biomed Mater Res 2007; 80(1): 206-215.

6 Jones JR. Review of bioactive glass: From Hench to hybrids. Acta Biomater 2015; 9 (Suppl: S53-82): 4.457-4.486.

7 Hench LL. The story of Bioglass. J. Mater Sci Mater Med 2006; 17: 967-978.

8 Wang Z, Sa Y, Sauro S, Chen H, Xing W, Ma X, Jiang $T$, Wang $Y$. Effect of desensitising toothpastes on dentinal tubule occlusion: a dentine permeability measurement and SEM in vitro study. J Dent 2010; 38: 400-410.

9 Sauro S, Watson TF, Thompson I. Dentine desensitization induced by prophylactic and airpolishing procedures: an in vitro dentine permeability and confocal microscopy study. J Dent 2010; 38(5): 411-422.

10 Banerjee A, Paolinelis G, Socker M, McDonald $F$, Watson TF. An in vitro investigation of the effectiveness of bioactive glass air-abrasion in the selective removal of orthodontic resin adhesive. Eur J Oral Sci 2008; 116(5): 488-492.
11 Paolinelis G, Watson TF, Banerjee A. Microhardness as a predictor of sound and carious dentine removal using alumina air abrasion. Caries Res 2006; 40(4): 292-295.

12 Efflandt SE, Magne P, Douglas WH, Francis LF. Interaction between bioactive glasses and human dentin. J Mater Sci Mater Med 2002; 13(6): 557-65.

13 Osorio R, Yamauti M, Sauro S, Watson TF, Toledano M. Experimental Resin Cements Containing Bioactive Fillers Reduce Matrix Metalloproteinase-mediated Dentin Collagen Degradation. J Endod 2012; 38(9): 1.227-1238.

Lee BS, Tsai HY, Tsai YL, Lan WH, Lin CP. In vitro study of DP-bioglass paste for treatment of dentin hypersensitivity. Dent Mater J Dec 2005; 24 (4): 562-9.

14 Lee BS, Chang CW, Chen WP, Lan WH, Lin CP. In vitro study of dentin hypersensitivity treated by Nd:YAP laser and bioglass. Dent Mater. 2005; 21(6): 511-9.

15 Kuo TC, Lee BS, Kang SH, Lin FH, Lin CP. Cytotoxicity of DP-Bioglass Paste Used for Treatment of Dentin Hypersensitivity. J Endod 2004; 33(4): 451-454.

16 Lee BS, Kang SH, Wang YL, Lin FH, Lin CP. In Vitro Study of Dentinal Tubule Occlusion with Sol-gel DP-bioglass for Treatment of Dentin Hypersensitivity. Dent Mater J 2007; 26(1): 52-61.

17 Curtis AR, West NX, Su B. Synthesis of nanobioglass and formation of apatite rods to occlude exposed dentine tubules and eliminate hypersensitivity. Acta Biomater 2010; 6(9): 3.740-3.746.

Chiang YC, Chen HJ, Liu HC, Kang SH, Lee BS, Lin FH, Lin HP, Lin CP. A Novel Mesoporous Biomaterial for Treating Dentin Hypersensitivity. J Dent Res 2010; 89(3): 236-240.

18 Bakry AS, Takahashi H, Otsuki M, Tagamie J. CO2 Laser Improves 45S5 Bioglass Interaction with Dentin. J Dent Res 2011; 90(2): 246-250.

19 Farmakis ET, Kozyrakis K, Khabbaz MG, Schoop $U$, Beer F, Moritz A. In Vitro Evaluation of Dentin Tubule Occlusion by Denshield and Neodymium-doped Yttrium-Aluminum-Garnet Laser Irradiation. J Endod 2012; 38(5): 662-666.

20 Vollenweider M, Brunner TJ, Knecht S, Grass RN, Zehnder M, IMFELD T, Stark WJ. Grass 
Remineralization of human dentin using ultrafine bioactive glass particles. Acta Biomater 2007; 3(6): 936-943.

Paolinelis G, Banerjee A, Watson TF. An in vitro investigation of the effect and retention of bioactive glass air-abrasive on sound and carious dentine. J Dent 2008; 36(8): 214-218.

21 Sauro S, Osorio R, Watson TF, Toledano M. Therapeutic effects of novel resin bonding systems containing bioactive glasses on mineraldepleted areas within the bonded-dentine interface. J Mater Sci Mater Med 2012; 23(6): 1.521-32.

22 Mousavinasab SM, Khoroushi M, Keshani F, Hashemi S. Flexural Strength and Morphological Characteristics of Resin-modified Glassionomer Containing Bioactive Glass. J Contemp Dent Pract 2011; 12(1): 41-46.
23 Hashimoto M, Lijima M, Nagano F, Ohno $\mathrm{H}$, Endo K. Effect of monomer composition on crystal growth by resin containing Bioglass. J Biomed Mater Res B Appl Biomate 2010; 94(1): 127-33.

24 Sauro S, Watson TF, Thompson I, Toledano $\mathrm{M}$, Nucci C, Banerjee A. Influence of air-abrasion executed with polyacrylic acid-Bioglass $45 S 5$ on the bonding performance of a resinmodified glass ionomer cement. Eur $\mathrm{J}$ Oral Sci 2012; 120(2):168-177.

25 Sauro S, Watson TF, Thompson I, Banerjee A. One-bottle self-etching adhesives applied to dentine airabraded using bioactive glasses containing polyacrylic acid: An in vitro microtensile bond strength and confocal microscopy study. J Dent 2012; 40(11): 896-905.

Submetido em: 30/09/2015

Aceito em: 13/11/2015 